\title{
Walnut diversity and breeding in Kyrgyzstan
}

\author{
Davlet Mamadzhanov", Sovet Kenzhebaev \\ National Academy Sciences of the Kyrgyz Republic «Jalal-Abad Scientific Center», str. mkr. Sputnik \\ B. Osmonova-130, Jalal-Abad, 715600, Kyrgyzstan
}

\begin{abstract}
The article provides information about the form diversity and selection of walnuts in the natural walnut forests of Kyrgyzstan. In walnutfruit forests, there is a wide variety of forms of walnut and other wild fruit species. The species and intraspecific diversity of wild fruit trees and shrubs allows selecting the best forms for creating highly productive plantations in various forest conditions in order to obtain high yields of nuts and other fruits. Methods of selection and criteria for selecting the best forms of walnuts are described.
\end{abstract}

\section{Introduction}

Walnut is an important nut crop, therefore a lot of work on studying local walnut populations and registering the best trees as varieties in recent decades has been carried out in many countries with developed walnut production. The most productive are the work of research teams from the USA, China, Iran, Turkey, France, Italy, Romania, Bulgaria, Moldova, Ukraine and a number of others.

In the United States, the Walnut Improvement Program is supported by the University of California, Davis, and the USDA in Winters, California. The objectives of the program include improving varieties for the California nut industry, developing better knowledge and methods to make breeding more efficient, developing and maintaining a variety of forms with traits useful for future breeding, and applying new molecular and genomic methods to improve walnuts.

The best varieties are the Chandler, Hartley and others, which begin their growing season 15-18 days later, then other. They were created by intervarietal hybridization.

The programs are aimed at various aspects of walnut improvement [1], breeding of varieties currently focusing on disease resistance and abiotic stress too.

In China, breeding targets are include early fruiting, high yields with high fruit quality and disease resistance. Walnuts are grown in twenty-one Chinese provinces or autonomous regions. The main ones are Xinjiang Autonomous Region, Yunnan, Shaanxi, Shanxi, Sichuan, Shandong and Hebei provinces. There is a long history of walnut cultivation in China. Indeed, Chinese botanists have identified and collected more than 800 forms (varieties) [2]. Each province has developed many local varieties, but the main ones of national interest include, for example, Bofeng, Bokexiang, Zha343, Luguang, Xiangling, Hanfeng, Wen185, Jinboxiang Series, Zhongling Series, Jinlong Series, and Luguo Series.

\footnotetext{
${ }^{*}$ Corresponding author: jangak@mail.ru
} 
In addition, the Shandong Institute of Pomology released 17 varieties in the period from 2003 to 2012, including Luguo 2 in 2012 from intraspecific hybridization and Luwen 1 in 2009 from interspecific hybridization (Zhang et al. 2014). The Xinjiang Autonomous Region program is also evaluating the benefits of secondary fruiting found in many early maturing dwarf walnuts [3].

In Turkey, at first breeding study (1971), various regions of Turkey were examined and 20 seedling genotypes were selected, including Yalova 1, Yalova 3, Bilecik and Şebin, which became the benchmark in many production areas in Turkey [4].

The National Walnut Breeding Program, started in 1998, introduced new late flowering and lateral fruiting varieties. Then, in 2000, a new breeding program was started to develop varieties with improved walnut quality traits, including higher kernel weight and shell thickness. In 2008, a breeding program aimed at developing varieties with higher yields, late leafing, improved nut quality and walnut blight tolerance carried out 13 crosses using Turkish genotypes and foreign varieties (Franket and Hartley). By these, 1340 hybrids were obtained, which were evaluated [5]. Three varieties were bred from the previous mass breeding program in 2009: Maras 18, Sütyemez 1 and Kaman 1 [6]. In Iran, most walnut trees have seed origin [7, 8]. The walnut improvement program began there in 1983 with the selection of superior genotypes from local forms in the Karaj, Shahrud, Mashhad and Urumye regions and pursued two main goals: the creation of new varieties and the development of effective methods of vegetative propagation [9]. In vitro propagation of walnuts plays a very important role in the multiplication of genotypes, and Iranian teams have been particularly involved in the development of these methods [10] in the fields of walnut genomics, breeding and identification of genetic traits of interest.

In India, 63 forms of walnut have been selected and tree that best meet all export standards was selected, such as walnut weight $(20.10 \mathrm{~g})$, walnut size $(45.45 \mathrm{~mm}$ x 42.07 $\mathrm{mm})$, shell thickness $(1.24 \mathrm{~mm})$, kernel recovery $(61.40 \%)$, light kernel proportion $(83.40 \%)$, protein content $(15.66 \%)$ and oil content $(68.42 \%)$. High resistance to anthracnose disease was also found [11]. Breeding work on walnuts with the involvement of the local gene pool is also carried out in Bulgaria, Romania and Serbia [12-14].

The presence of natural walnut forests in Kyrgyzstan makes it promising to search for new forms valuable for breeding. In the south of Kyrgyzstan, on the slopes of the Fergana and Chatkal ranges of the Tien Shan mountain system, on an area of over 333 thousand hectares (forest fund inventory, 2015), natural walnut-fruit forests grow. They are mainly represented by two separate large areas: Arslonbobo-Kugart and Khoja-Ata, which are located on the slopes of the mountains from east to west. In terms of their area and variety of tree species, these forests are the only ones in the world.

The remarkable oasis of the Fergana fruit forests has long attracted the attention of Russian scientists. At the end of the 18th century, these forests were visited by academician S.I. Korzhinsky. In the description of these forests, S.I. Korzhinsky notes the exceptional abundance of fruit trees: "... it is as if you are driving through a continuous orchard for tens of miles," and then "... these peculiar deciduous forests constitute, as it were, a separate oasis, representing, in all likelihood, only a relic of deciduous forests of the Tertiary period, once, no doubt, widespread, but now so little in harmony with the general appearance of the nature of Turkestan."

In the walnut-fruit forests there are more than 130 species of arboreal and shrub species forming various forest communities, 82 shrubs and 48 arboreal species. The family of Rosaceae, numbering up to 50 species, is especially richly represented.

Many species are forest-forming species and the areas of the main species are (accounting for the forest fund for 2015): walnut (Juglans regia.L) -40.5 thousand hectares, pistachio (Pistacia vera) -33.1 thousand hectares, species apple (Malus) -15.0 thousand hectares, hawthorns $($ Crataegus $)-10.6$ thousand hectares, maple $($ Acer $)-30.3$ 
thousand hectares, Tien Shan spruce $($ Picea $)-10.8$ thousand hectares, Semenov fir (Abies) -3.7 thousand hectares, juniper (Juniperus) - 53.3 thousand hectares, almonds $(P$. amygdalus $)-2.1$ thousand hectares and other tree and shrub species -134 thousand hectares.

The issues of studying the form and genetic diversity and selection of nut-bearing breeds to increase the productivity of forest crops and plantations and the preservation of biodiversity of vegetation remain relevant at the present time.

\section{Materials and methods}

Natural walnut forests in the belt of walnut-fruit forests and cultural plantations growing in valley conditions are an object for studying the form diversity and selection of the prospecting walnut genotypes.

To select the best forms of walnut, surveys are carried out in natural and cultural plantings. First of all, trees that are fruitful and regularly bearing fruit with a high yield are selected. Among them, by eye assessment, trees not damaged by frost and diseases are identified. Samples of fruits are taken from these trees to determine their commercial qualities.

The assessment of the selected walnut trees is carried out for 3-4 years, during which phenological observation is carried out and all their main signs and properties are checked: flowering period, yield, regularity of fruiting, frost resistance, drought resistance and disease resistance, and fruit quality.

If the signs and properties for which they were distinguished are confirmed during 3-4 years of observations, then the tree is examined to be included in the category of the best promising forms.

Selection criteria for the best forms:

1. Frost resistance - resistant to winter frosts and spring frosts, late flowering in comparison with other nearby growing trees,

2. Drought resistance - relatively resistant to drought, growing in arid areas of southern exposure and in the lower foothill areas,

3. Immunity - resistant to fungal, bacterial and other diseases, frosts,

4. Regularly bearing fruit - having a harvest annually and in years with late spring

5. Early maturity,

6. Economically valuable traits - high yield and quality of the fruit,

a) large-fruited nuts with a diameter of at least $34 \mathrm{~mm}$,

b) with easily removable kernels,

c) with thin-shelled nuts, with a shell thickness of no more than $1.5 \mathrm{~mm}$,

d) kernel color light (light yellow, yellow),

e) with nuts of good taste.

By interviewing the tenants of forest plots, one can obtain information about the yield, the regularity of fruiting and the quality of the fruits of selected walnut forms.

\section{Results and discussion}

The area of walnut-fruit forests in the south of Kyrgyzstan is, in the opinion of most researchers studying it, a unique natural phenomenon and are a relic of the Tertiary period. Considering the huge form diversity within each species, it can be argued that this area has the greatest value as a custodian of the gene pool and, according to scientists, is one of the centers of origin of many cultivated fruit plants in Central Asia. 


\subsection{About walnut diversity in fruit-tree forests}

During the research, it was revealed that in the zone of walnut-fruit forests, the local population distinguishes several groups of walnut forms. At the same time, it was taken into account how these groups of forms distinguish farmers in the local language. In total, 4 groups of walnut forms were identified: Kanyrty zhangak, Tizme zhangak, Chukuma zhangak and large-fruited forms.

Kanyrty (Easy to extract) - trees of seed origin, of different ages. Nuts in this group are medium in size, full of kernels, low shell ribbing and light kernels. The average fruit weight is $8-13 \mathrm{~g}$. The nut is round in shape and smoothed seams. The kernel is easily removed, whole and in half. Shell thickness - 1.0-1.5 mm.

Tizme zhangak (Thin-shelled) - Seed trees, uneven ages. Attracts the attention of farmers with its thin shell. Shell thickness less than $1.0 \mathrm{~mm}$. The fruits are small and medium. The average weight of the fruit is $7-9 \mathrm{~g}$. The kernel is removed very easily.

Chukuma (hard shell) - widespread. It attracts little because they have fruits with hard shells and kernels are very difficult to remove from the shell. This is due to the fact that the inner layer of the endocarp and the septum of the fetus in this form are lignified. The average weight of nuts is $8-12 \mathrm{~g}$. Trees in this group are relatively resistant to frost and disease.

Large-fruited forms - nuts are large, ovoid, light brown in color. The average weight of nuts is $12-18 \mathrm{~g}$. The shell is thick, the kernel is easily removed from the shell. The shell thickness is more than $2 \mathrm{~mm}$. The kernel yield from the shell is low - 30-40\%.

In natural walnut plantations and walnut cultures, there is a wide variety of walnuts, among which there may be zones of walnut-fruit forests more adapted to climatic conditions and climate change over many years and therefore it is possible to replenish with new promising forms of walnut in a complex of economically valuable traits and biological properties (frost resistance, drought resistance, resistance to diseases and pests, late flowering, early entry into fruiting, yield and high quality of the fruit).

In this regard, the identification, study and isolation of valuable forms in breeding work remains one of the important tasks at the present stage of walnut farming development.

\subsection{Walnut breeding in Kyrgyzstan}

Walnut breeding in southern Kyrgyzstan has been carried out since the 30s of the last century. After the organization (1935) in the walnut-fruit forests zone of the experimental forest-fruit station VNIISS, planned work began on the selection of walnuts. In those years, works were published on the results of the walnut best forms selection by G.M. Aksakov (1940), Momot, (1940), A.F. Zarubin (1954). Their selection was based, first of all, on the morphological characteristics of the fruits. Information about many previously selected forms in the 40-50s has not been preserved.

D. I.Prutensky and V. S.Shevchenko (1976) selected and described more than 220 walnut forms, of which 6 forms were submitted for state variety testing. These varieties are Ak-Tereksky, Gavinsky, Dessertny, Oshsky, Ostrovershinny, Uygursky (Table 1). Among the selected forms, there are 20 early-ripening, two forms according to especially important characteristics of the Bomb: very large nuts with an average weight of $20 \mathrm{~g}$ and racemose the fruits are collected in a raceme of 8-10 fruits. 
Table 1. Fruit quality of the V.S. Shevchenko breeding best walnut varieties.

\begin{tabular}{|l|c|c|c|c|}
\hline Varieties/forms & $\begin{array}{c}\text { M.Weight } \\
\text { of fruits, } \mathrm{g}\end{array}$ & Fat, $\%$ & Shell tickness, $\mathrm{mm}$ & Kernel ratio, \% \\
\hline Ak-Tereksky peaked & 11,7 & 68,4 & 1,5 & 47 \\
\hline Uygursky & 14,1 & 67,8 & 1,5 & 45 \\
\hline Ak-Tereksky & 10,5 & 68,0 & 1,6 & 45 \\
\hline Desertny & 12,0 & 67,0 & 1,4 & 50 \\
\hline Gavinsky & 10,0 & 68,8 & 1,2 & 49 \\
\hline Oshsky & 10,6 & 67,5 & 1,1 & 48 \\
\hline
\end{tabular}

The selected best forms of walnuts are distinguished by their yield, large-fruited, high kernel percentage, ease kernel extraction. According to biological properties, there are lateflowering varieties, relatively immune.

Previously selected walnut best forms are combined according to a number of characteristics - late vegetative, immune, large-fruited, early-growing, racemose and thinshelled. Basically, large-fruited forms were selected, and this indicates that in the past more attention was paid to the selection of the best forms according to the morphological characteristics of the fetus. A small number of thin-shelled, immune, racemose and lateflowering forms were selected. Early-fruiting forms were selected in valley conditions, where climatic conditions are more optimal for the growth and fruiting of early-fruiting forms than in mountain conditions, where early-fruiting forms bear poorly due to frosts, unfavorable weather conditions during the flowering period, a short growing season compared to valley conditions.

Regarding late-flowering forms, the researchers noted that by a single selection in fruitbearing plantations it is difficult to distinguish forms that, in addition to the good qualities of the fruit, will also be significantly distinguished by late flowering, increased winter hardiness, and immunity against diseases. Thus, according to the observations of G. M. Aksakov, in southern Kyrgyzstan, different walnut trees growing in the same conditions do not differ significantly in terms of growing season, and the possibility of selection for this property is very limited. A.F Zarubin also points out that the selection in the forests of southern Kyrgyzstan of late-flowering walnut forms resistant to spring frosts, begun back in 1937 by the support point of the Institute of Dry Subtropics, did not give positive results.

However, in natural plantations, there are forms that start growing a few days later, so it is necessary to continue work on the selection of late-flowering walnut forms. In small numbers, racemose, thin-shelled and burl forms of walnuts were selected. The selected forms for especially important characteristics are promising for their use in breeding work when developing new varieties of walnuts.

In 1999-2004. in the belt of walnut-fruit forests, more than 18 walnut forms were selected, which are distinguished by the best economically valuable traits and biological properties. Of the selected walnut forms, 8 forms were identified as the best promising (in terms of a complex of characteristics), presented in Table 2. These forms bear fruit regularly, are fruitful, relatively frost-resistant and have good fruit quality. 
Table 2. Best walnut forms selected during 1999-2004.

\begin{tabular}{|c|c|c|c|c|}
\hline Forms & Fruit weight, $\mathrm{g}$ & Kernel ratio, $\%$ & Fat, $\%$ & $\begin{array}{c}\text { Shell thickness, } \\
\mathrm{mm}\end{array}$ \\
\hline 3-A & 10,6 & 47,4 & 69,5 & 1,5 \\
\hline 4-A & 10,0 & 57,9 & 68,8 & 1,3 \\
\hline 7-A & 10,3 & 44,2 & 69,6 & 1,6 \\
\hline 10-A & 11,5 & 54,7 & 69,9 & 1,1 \\
\hline 11-A & 14,5 & 47,7 & 68,8 & 1,6 \\
\hline 12-A & 13,8 & 44,1 & 65,3 & 1,8 \\
\hline 14-A & 9,1 & 51,1 & 67,8 & 1,1 \\
\hline 2- K & 13,5 & 46,7 & 66,6 & 1,6 \\
\hline
\end{tabular}

The selected best varieties and walnut forms have a good fruit quality and comply with international standards. As noted in the descriptions, the fruit weight ] of varieties and walnut forms is more than $10 \mathrm{~g}$, the kernel ratio is more than $45.0 \%$, the kernel is easily removed from the shell, kernels are light yellow and yellow. According to biological characteristics, the selected varietal trees are late flowering, more resistant to frost, less damaged by diseases and bear fruit well. The selected new forms were identified according to a complex of economically valuable traits (yield and fruit quality) and biological properties - late flowering, frost resistance, immunity, regularity of fruiting and precocious. Among the selected forms, there are forms that bear fruit without pollination, i.e. apomictic. It is known that some plants, including woody ones, can reproduce without the participation of males, i.e. without pollination and fertilization. This phenomenon is called apomixis. The offspring obtained in this way gives a complete copy of the mother plant. Selection of homogamous forms of walnut is of great interest for science and industry. With homogamous flowering, self-pollination of female flowers occurs and seed reproduction of such forms allows inheriting the characteristics of the mother tree.

\subsection{About Kyrgyzstan walnut genetic diversity}

Genetic diversity studies in South and Central Asia, including studies of walnut populations in the walnut-fruit belt of Kyrgyzstan with Austrian colleagues from the Forest Genetics Department of the Austrian Forest Research Center, show strong population differentiation between regions and indicate a strong anthropogenic impact on existing genetic resources.

The nuts morphology also varies by region. Based on the molecular variation and nuts morphology, it has been suggested that the South Asian region is likely the walnut source. Future research should focus on populations in South and Central Asia, including appropriate conservation measures for this important genetic resource in these regions [15].

\section{Conclusion}

Walnut forests are of great value both in terms of raw materials and water protection, and from a scientific point of view. For the local population, the walnut-fruit area is the only source of income.

From a forestry point of view, many areas of walnut plantations are in an unsatisfactory sanitary condition, and ripe and overripe plantations prevail in terms of age.

Unfortunately, at present, this unique genetic diversity is under the threat of gradual disappearance, due to a greater extent to human activities for excessive harvesting of fruits, tree felling due to the high demand of the local population for firewood, widespread grazing and lack of forest regeneration, etc. 
The main task at the present time is to preserve these unique forests and expand the forested area by creating forest crops and high-yielding plantations in all areas suitable for growing walnuts. Below the region of walnut-fruit forests, adjacent territories have a large number of open areas, open spaces and other areas where the main species (walnut) has changed to secondary ones. In such areas, it is necessary to carry out work to expand the areas of walnuts and other nut-bearing breeds.

An important role in the creation of forest crops and industrial walnut plantations is played by the selection of the best forms and the use of previously selected varieties and forms with better biological properties (abundant fruiting, resistance to diseases and low temperatures, drought resistance, late flowering, early maturity) and fruit quality (largefruited, ease of kernel extraction, high kernel yield, kernel flavor, etc.).

It is necessary to continue work on the study of the form and genetic diversity, carry out work on the selection of nut-bearing breeds, it is necessary to pay attention to the selection of fast-growing forms of walnut that are resistant to climatic conditions, improve the breeding methods and technologies of vegetative reproduction of the walnut and other nutbearing breeds, the use of innovative methods of selection and vegetative reproduction.

\section{References}

1. C. Leslie, G. McGranahan, W. Hackett et al., Walnut Res Rep (2015) https://ucanr.edu/sites/cawalnut/category/genetic_breeding/

2. X. Chen, L. Xu, S. L. Zhang, Z. Q. Liu, Acta Hortic, 1050, 89-94 (2014) 0.17660/Acta Hortic.2014.1050.10

3. G. Wang, J. Y. Wang, Q. He, et al, Acta Hortic, 1050, 113-121 (2014) 10.17660/Acta Hortic.2014.1050.13

4. Y. Akça, Acta Hortic 1050, 139-142 (2014) https://doi.org/10.17660/ActaHortic.2014. 1050.16

5. Y. Akça, M. Sütyemez, S. Yilmaz, H. Karadag, Conference: AGROSYM, 461-466 (2016) 10.7251/AGRENG1607064

6. M. Sütyemez, Hortscience, 51(10), 1301-1303 (2016) https://doi.org/10.21273/HORT SCI10972-16

7. M. Ghasemi, K. Arzani, D. Hassani, Crop Breed J, 2, 119-124 (2012) 10.22092/CBJ. 2012.100429

8. R. Mahmoodi, D. Hassani, M. R. Dadpour, M. Zeinalabedini, F. Z. Nahandi, onference: Study of genetic diversity of Iranian walnut (Juglans regia L.) collection by using morphological traits At: Iran (2019) https://www.researchgate.net/publication/335812 696_Study_of_genetic_diversity_of_Iranian_walnut_Juglans_regia_L_collection_by_us ing morphological_traits

9. D. Hassani, R. Dastjerdi, R. Haghjooyan et al, Acta Hortic, 1050, 95-102 (2014) https://www.researchgate.net/publication/257364438_genetic_Improvment_of_Persian_ walnut_in_iran

10. K. Payghamzadeh, S.K. Kazemitabar, Afr J Biotechnol, 10, 290-311 (2011) https://www.researchgate.net/publication/267835088_In_vitro_propagation_of_walnut_ -A_review

11. R. M. Sharma, K. Kour, B. Singh, S. Yadav, N. Kotwal et al., AJCS 8(2), 257-262 (2014) http://www.cropj.com/sharma_8_2_2014_257_262.pdf

12. S. I. Gandev, V. Arnaudov, D. Serbezova, ActaHortic, 1074(1074), 135-139 (2015) 10.17660/ActaHortic.2015.1074.20

13. S. Cosmulescu, South west J Hortic Biol Environ, 4 (2), 117-126 (2013) https://biozoojournals.ro/swjhbe/v4n2/04_swjhbe_v4n2_Cosmulescu.pdf 
14. S. Cerović, B. Gološin, J. N. Todorović, S. Bijelić, V. Ognjanov, HORTSCI, 37(1), 2-5 (2010) 10.17221/25/2009-HORTSCI

15. W. Roor, H. Konrad, D. Mamadjanov, T. Geburek, Journal of Heredity, 1-14 (2017) 10.1093/jhered/esw122 